doi: $10.2306 /$ scienceasia1513-1874.2012.38.373

\title{
Bias correction of radar rainfall estimates based on a geostatistical technique
}

\author{
Ratchawatch Hanchoowong $^{\mathrm{a}}$, Uruya Weesakul ${ }^{\mathrm{a}}$, Siriluk Chumchean ${ }^{\mathrm{b}, *}$ \\ a Department of Civil Engineering, Thammasat University Pathumthani, Thailand 12121 \\ b Department of Civil Engineering, Mahanakorn University of Technology Bangkok 10530 \\ *Corresponding author, e-mail: siriluk@mut.ac.th
}

Received 15 Feb 2012

Accepted 3 Sep 2012

\begin{abstract}
Various types of rainfall characteristic have different rainfall drop size distributions (DSDs). DSDs that are measured by radar have a fundamental influence on parameters of the $Z-R$ relationship; using a climatological $Z-R$ relationship to estimate radar rainfall can lead to bias in radar rainfall estimates. This paper attempts to remove the source of bias in radar rainfall estimates due to an uncertain $Z-R$ relationship by applying a local bias adjustment factor to a region that has the same climatological rainfall characteristic. Recorded historical daily rainfall data from 188 uniformly distributed rain gauges located under the radar umbrella and its vicinity were used for describing the climatological spatial pattern of rainfall in the study area based on kriging approaches. It was found that a simple kriging technique with the isotropic Bessel- $J$ semivariogram model was the best method to classify climatological patterns of rainfall characteristic of the study area and therefore it has been used for identifying local bias correction areas of the proposed hourly local bias (HLB) correction method. Performances of different bias correction methods with various levels of complexity were evaluated from 500 of the calibrated and cross-validated gauges of the validated data set, selected randomly. These methods include mean field bias correction (MFB), hourly mean field bias correction (HMFB), hourly range dependent mean field bias correction (HRMFB), and HLB correction. Forty-four rainfall events recorded during 2003-2005 from the S-band Pimai radar located in Nakhon-Ratchasima Province, Thailand, and 50 automatic rain gauges were used in this study. The results of this study showed that, on average, the proposed HLB method could improve accuracy of radar rainfall estimates by $16.7 \%, 14.3 \%, 2.8 \%, 0.4 \%$ for the calibrated gauges, and by $11.8 \%, 10.2 \%, 9.4 \%, 4.1 \%$ for the cross-validated gauges when compared to non-bias corrected, MFB, HMFB, and HRMFB methods, respectively.
\end{abstract}

KEYWORDS: bias adjustment method, climatological rainfall characteristic, kriging

\section{INTRODUCTION}

The natural phenomenon of rainfall is a very complex process. In this sense, measuring rainfall using rain gauges can provide rainfall data with an acceptable accuracy in specific locations covering areas of only $200 \mathrm{~cm}^{2}$ which could not be used to represent spatial rainfall correctly. A number of conventional spatial rainfall estimation methods based on rain gauge data such as arithmetic average and Thiessen polygons have been used in order to give spatial rainfall information. The arithmetic average method is suitable for a plain area where the rain gauge network is uniformly distributed and rainfall measured at each rain gauge is not much different from average rainfall, while the Thiessen polygon method has difficulty in calculating new weighting factors when the available rain gauge network has been changed. Besides, neither of these methods accounts for topography and spatial rainfall characteristic, which leads to inaccuracies in the derived rainfall, especially for non-spatially uniform rainfall. An isohyetal method ${ }^{1}$ is still a useful and fairly accurate technique for determining spatial distribution of precipitation affected by topography. The isohyetal method gives more accurate spatial rainfall than the arithmetic average and Thiessen polygon methods ${ }^{2}$. However, the accuracy of the isohyetal contour map still depends on accurate knowledge of storm morphology and rainfall characteristic.

In the last 40 years, geostatistical techniques have also been applied to estimate rainfall from rain gauge data. The advantage of these methods over the conventional methods is that they account for spatial correlations between observations when estimating rainfall of unsampled points. The best known procedure for spatial rainfall estimation based on geo- 
statistical approaches is called "kriging"3-5. In this method, a semivariogram is used to quantify spatial correlations between measured rain gauge rainfall data. Once a mathematical function has been fitted to the experimental semivariogram, the model can be used to estimate rainfall at un-gauged locations. Consequently, spatial rainfall data can be calculated over specified areas. However, using geostatistical methods to estimate spatial rainfall with an acceptable accuracy requires a dense and uniformly distributed rain gauge network which is limited in the most remote catchments.

In the last two decades, weather radar has been widely used to estimate rainfall. The use of rainfall data obtained from a weather radar network is an efficient way of observing detailed structure and behaviour of rainfall field with high spatial and temporal resolutions covering a large area. However, a radar does not measure rainfall directly; instead, it measures backscattered energy from precipitation particles above the ground surface. Because the radar measures volumetric reflectivity of hydrometeors above the ground, radar rainfall estimates are subject to various sources of errors. These errors include reflectivity measurement error, $Z-R$ conversion error, and residuals error in radar rainfall when compared to rain gauge data ${ }^{6}$. Many studies have been performed to reduce the error in measured reflectivity ${ }^{7-9}$ and the $Z-R$ conversion error ${ }^{10-12}$. After these two sources of error correction have been performed, it is generally necessary to use rain gauge observations to bias correction of initial radar rainfall estimates for increased accuracy of radar rainfall. Different corrective measures such as mean field bias correction ${ }^{13-15}$, range dependent bias correction ${ }^{16-18}$, local bias correction ${ }^{19-21}$, spatio-temporal bias correction ${ }^{22-24}$, and bias correction methods that account on the magnitude of rain rate ${ }^{25,26}$ have been proposed to remove bias in radar rainfall estimates when compared with rain gauge data. Recently, radar-gauge merging methods have been introduced to produce more accurate rainfall fields ${ }^{27-29}$. In their studies, kriging was applied to incorporate rain gauge and radar data for producing final rainfall field. Previous studies ${ }^{4,30}$ showed that the performance of kriging can be improved by using external information (e.g., elevation) to estimate the trend of the rainfall.

Various types of rainfall characteristic have different rainfall drop size distributions (DSDs) ${ }^{31-33}$. Since DSDs that are measured by radar have fundamental influence on parameters of the $Z-R$ relationship, using a climatological $Z-R$ relationship to estimate radar rainfall can lead to bias in radar rainfall estimates.
This paper attempts to remove the source of bias in radar rainfall estimates due to an uncertain $Z-R$ relationship by applying a local bias correction factor to a region that has the same climatological rainfall characteristic. Recorded historical daily rainfall data from 188 uniformly distributed network of rain gauges located under the radar umbrella and its vicinity area were used for describing climatological spatial patterns of rainfall of the study area based on kriging approaches. Each area that is classified to have the same rainfall characteristic was then used for calculating hourly local bias correction factors to be used for the proposed hourly local bias correction method (HLB). Accuracy of bias-corrected radar rainfall estimates obtained from different bias correction methods with various levels of complexity was evaluated. These methods include: mean field bias correction (MFB), hourly mean field bias correction (HMFB), hourly range dependent mean field bias correction (HRMFB), and hourly local bias correction (HLB). Effectiveness of these bias adjustment methods was compared by considering RMSE between bias-corrected radar rainfall estimates obtained from each method and the corresponding rain gauge rainfall. Ten rainfall occurrences during 2004-2005 recording from the Sband Pimai radar site located in Nakhon-Ratchasima Province, Thailand, annual rainfall of a network of 188 daily rain gauges and 50 automatic rain gauges (as illustrated in Fig. 1) were used in the analysis.

\section{APPLICATION OF GEOSTATISTICAL TECHNIQUES TO BIAS CORRECTION}

The way topography modifies the spatial pattern of rainfall depends on meteorological characteristics of incident airflow, such as the air moisture content, temperature, wind speed, and direction of movement ${ }^{34}$. Several studies $4,35,36$ have found that topographical features influence rainfall characteristic by the orography effect of mountainous terrain. This orography effect causes the air to be lifted vertically, and condensation occurs due to adiabatic cooling, therefore it tends to increase rainfall with increasing elevation. This study considers that topography has influence on the spatial pattern of rainfall and therefore leads to different climatological rainfall characteristic for each topography. Several previous studies showed that geostatistical approaches are the methods for describing spatial structure of many natural phenomena including rainfall fields ${ }^{4,37,38}$. Kriging is one of the most efficient geostatistical estimation techniques that provides the best unbiased linear estimations. All of kriging methods require spatial models such as a semivariogram model to provide spatial depen- 


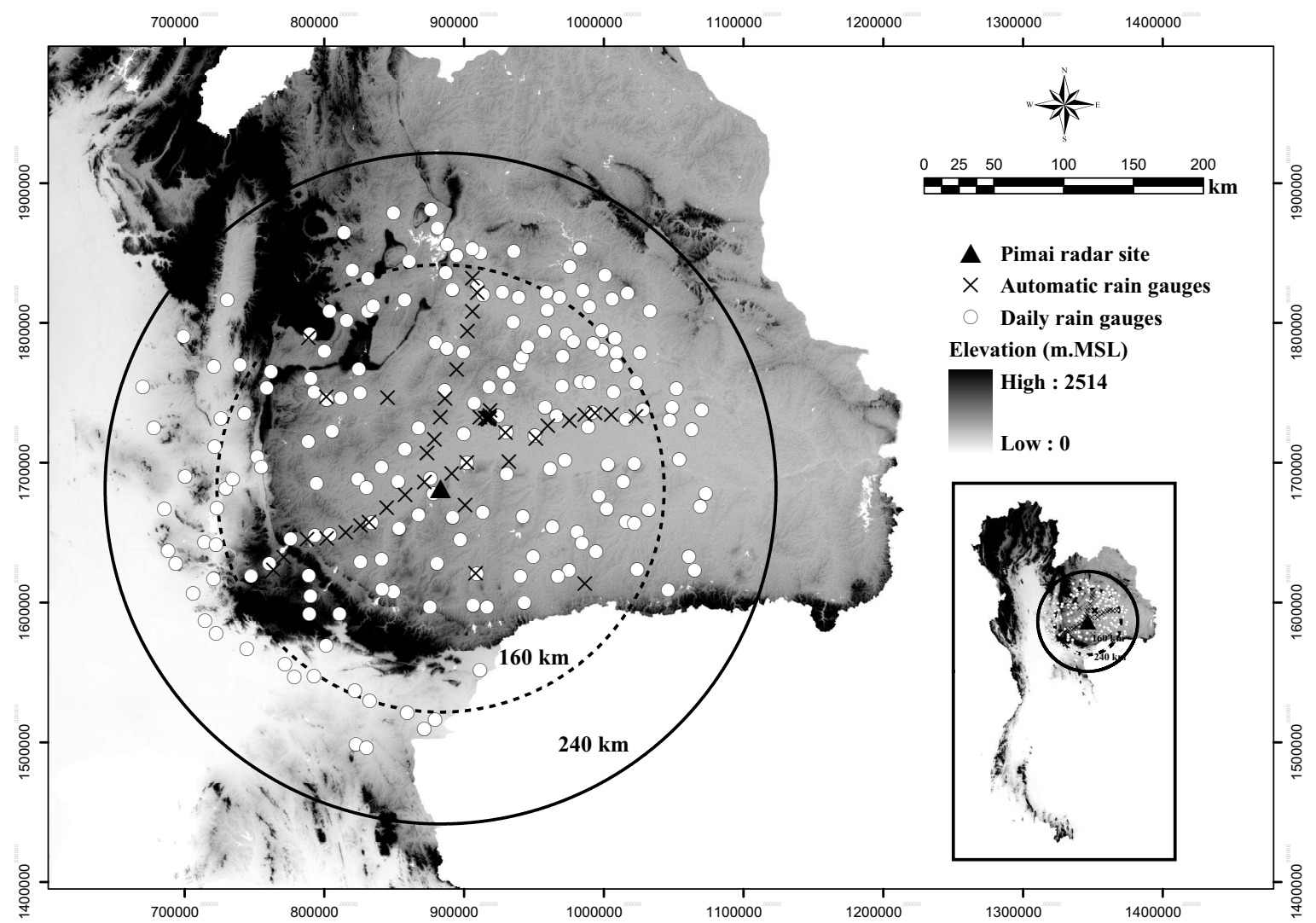

Fig. 1 Locations of the Pimai radar site (small triangle), daily rain gauge network (small circles), and automatic rain gauges (small crosses).

dence between observed data that have been used to calculate unsampled data points. Spatial rainfall estimates using different kriging and semivariogram models could result in different errors of the estimates. Therefore, it is necessary to investigate the most suitable kriging method that can provide the most accurate spatial rainfall estimates of the study area. The simple kriging method gave most accurate spatial pattern rainfall estimates when compared with other kriging methods ${ }^{39}$. In this study, 50 years' historical rainfall data of the network of 188 daily rain gauges were used to derive climatological spatial pattern of rainfall under the radar umbrella based on simple kriging approach. The basic simple kriging estimator is defined by Goovaerts ${ }^{40}$ as:

$$
\hat{Z}_{\mathrm{SK}}(u)=m+\sum_{\alpha=1}^{n(u)} \lambda_{\alpha}^{\mathrm{SK}}(u)\left[Z\left(u_{\alpha}\right)-m\right],
$$

where $u$ is the location vector for the estimation point, $u_{\alpha}$ is the location vector for local neighbouring points, $m$ is the trend component, $n(u)$ is the number of data points in the local neighbourhood used for the estimation of $\hat{Z}_{\mathrm{SK}}(u)$, and $\lambda_{\alpha}^{\mathrm{SK}}(u)$ is the simple kriging weight assigned to datum $Z\left(u_{\alpha}\right)$ for the estimation of location $(u)$, which can be found from:

$$
\begin{aligned}
\sum_{\beta=1}^{n(u)} \lambda_{\beta}^{\mathrm{SK}}(u) C\left(u_{\alpha}-u_{\beta}\right)= & C\left(u_{\alpha}-u\right), \\
& \alpha=1, \ldots, n(u),
\end{aligned}
$$

where $C\left(u_{\alpha}-u_{\beta}\right)$ is the covariance between local neighbourhood data points, $C\left(u_{\alpha}-u\right)$ is the covariance between local neighbourhood data points with an estimated point. This equation can be set in matrix form as:

$$
\lambda_{\mathrm{SK}}=K^{-1} k,
$$

where $\lambda_{\mathrm{SK}}$ is the simple kriging weight, $K$ is the covariance between local neighbourhood data points in matrix form, with components $K_{r, y}=C\left(u_{r}-u_{y}\right)$, and $k$ is the covariance between local neighbourhood data points with an estimated point in matrix form, with components $k_{r}=C\left(u_{r}-u\right)$. The covariance 
can be calculated as:

$$
C(h)=\operatorname{sill}-\gamma(h),
$$

where $C(h)$ is the covariance between data points at a distance $h$, sill is the semivariance that the semivariogram model reaches when it levels off, and $\gamma(h)$ is the semivariance calculated at a distance $h$ from the semivariogram model, which can be defined as:

$$
\gamma(h)=0.5 \operatorname{Var}[Z(x)-Z(x+h)]
$$

where Var is the variance. If two locations, $(x)$ and $(x+h)$, are close to each other in terms of the distance measure of $d(x, x+h)$, then $Z(x)$ and $Z(x+h)$ are expected to be similar, so the difference in their values, $Z(x)-Z(x+h)$, will be small. As $(x)$ and $(x+h)$ get farther apart, they become less similar, so the difference in their values, $Z(x)-Z(x+h)$, will become larger. This can be explained in Fig. 2, which shows the anatomy of a typical semivariogram ${ }^{41}$. It is to be noticed that the variance of the difference increases with distance, so the semivariogram can be thought of as a dissimilarity function. There are several terms that are often associated with this function, and they are also used in ARCGIS Geostatistical Analyst. The height that the semivariogram reaches when it levels off is called the sill. It is often composed of two parts: a discontinuity at the origin, called the nugget effect, and the partial sill, which added together give the sill. The nugget effect can be further divided into measurement error and microscale variation. The nugget effect is simply the sum of measurement error and microscale variation and, since either component can be zero, the nugget effect can be comprised wholly of one or the other. The distance at which the semivariogram levels off to the sill is called the range ${ }^{41}$.

In this study, the software package ARCGIS 9.3 and ARCGIS Geostatistical Analyst Extension were used in applying the simple kriging method to estimate parameters of 11 empirical semivariogram models including circular, spherical, tetraspherical, pentaspherical, exponential, gaussian, rational quadratic, hole effect, Bessel- $K$, Bessel- $J$, and stable for producing climatology spatial patterns of average annual rainfall based on rainfall data from 188 daily rain gauges network. The most accurate climatological spatial pattern of average annual rainfall in the study area is selected to use for identifying local bias correction areas of the proposed radar rainfall estimation process (HLB method).

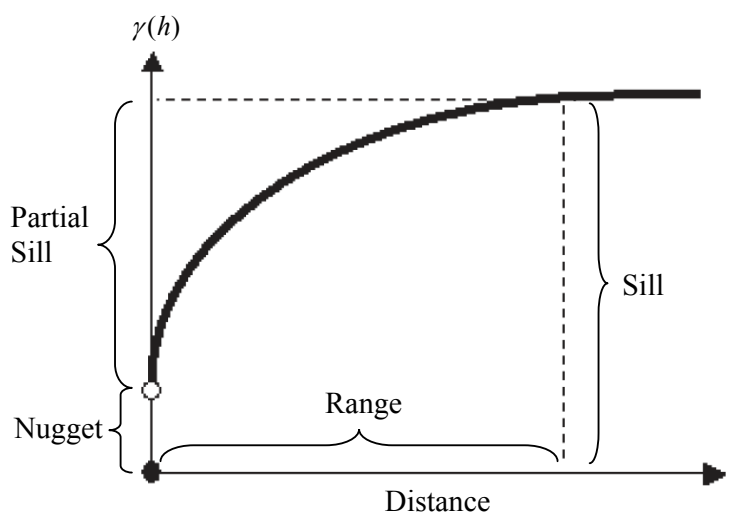

Fig. 2 The anatomy of a typical semivariogram ${ }^{41}$.

\section{DATA COLLECTION}

\section{Rain gauge data}

Average annual rainfall data obtained from the network of 188 daily rain gauges during 1960-2009 were used to determine the climatological spatial pattern of rainfall of the study area. These rain gauges belong to the Royal Irrigation Department and are located within a $240 \mathrm{~km}$ radius of the Pimai radar site in Nakhon-Ratchasima Province, Thailand, as illustrated in Fig. 1. Quality control of rain gauge rainfall data was performed using double mass curve method. Only reliable radar and rain gauge data were used in the analysis. It was found that rainfall data recorded from all of 188 daily rain gauges were reliable and they can be used in the analysis. Since kriging techniques are suitable to be used with uniformly distributed rain gauge network and the average annual rainfall of rain gauges should be normally distributed, KolmogorovSmirnov statistic was used to test for normality of the distribution of average annual rainfall data of these 188 rain gauges. The significant level for the Kolmogorov-Smirnov test showed a $p$-value of 0.20 which was higher than 0.05 , hence normality was assumed. Consequently, these rainfall data can be used to derive the climatological pattern of spatial rainfall of the study area based on kriging methods.

Fifty automatic tipping bucket rain gauges operated by the Bureau of Royal Rainmaking and Agriculture Aviation (BRRAA) during 2003-2005 were used to test the effectiveness of different bias adjustment methods. Quality control of rain gauge rainfall data was performed using the double mass curve method and plots of time series. Accumulated monthly rainfall of a tested rain gauge and its adjacent rain gauges were plotted; if no break was shown in the slope of the double mass curve, then rainfall data of the 
tested rain gauge were considered to be consistent with rainfall data of its adjacent stations and they can be used in the analysis. From rain gauge data quality control, it was found that all of these 50 rain gauges rainfall data were reliable. However, one rain gauge located $0.07 \mathrm{~km}$ from the radar site was within the blinding area of radar rainfall measurement. This rain gauge was excluded from this study. Locations of 49 automatic rain gauges are shown in Fig. 1.

\section{Radar reflectivity data}

The $2.5 \mathrm{~km}$ constant altitude plan position indicator (CAPPI) reflectivity data of rainfall events that occurred within $160 \mathrm{~km}$ from the Pimai radar during 2003-2005 were used in this study. The radar belongs to BRRAA and is located in the Pimai district of Nakorn-Ratchasima Province in the Northeast of Thailand. It is an S-band radar that transmits radiation with a wavelength of $10.7 \mathrm{~cm}$ and beam width of $1.2^{\circ}$. The $2.5 \mathrm{~km}$ CAPPI data used in this study have $1 \mathrm{~km}^{2}$ spatial resolution and 6 min temporal resolution. Quality control of reflectivity data was performed. The errors due to radial anomaly, ANAPROP, other signals that do not represent rainfall, and errors caused by electronic problems were removed from the measured reflectivity data. Reflectivity data that were greater than $53 \mathrm{dBZ}$ were limited to $53 \mathrm{dBZ}$ to mitigate contamination from hail ${ }^{42}$. To avoid the effect of noise in the measured radar reflectivity, the measurements lower than $15 \mathrm{dBZ}$ were excluded from the analysis. Based on quality control of both reflectivity and rain gauge data, 44 rainfall occurrences during 2003-2005 were selected for use in the analysis. Details of these rainfall events are presented in Table 1.

\section{METHOD}

Bias correction approach is the last procedure in realtime radar rainfall estimation process. However, this approach needs to be performed after errors in measured reflectivity and $Z-R$ conversion error have been removed $^{6,17,43}$. In this study, errors in measured reflectivity were eliminated through the radar reflectivity quality control process as explained in the previous section. The $Z-R$ conversion error has been removed by using the climatological $Z-R$ relationship of the Pimai radar. Forty-four rainfall events that passed both rain gauge and radar quality control processes were used in this study. These rainfall events were divided into 2 data sets. In order to reduce the effect of storm types on the performance of bias adjustment methods, each data set was composed of various types of rainfall including cumulonimbus, cumulus, and nimbostratus
Table 1 Forty four rainfall events used in the analysis.

\begin{tabular}{|c|c|c|c|c|}
\hline Start time & $\begin{array}{c}\text { Duration } \\
\text { (min) }\end{array}$ & $\begin{array}{l}\text { Number } \\
\text { of gauges }\end{array}$ & $\begin{array}{c}R_{\mathrm{avg}} \\
(\mathrm{mm} / \mathrm{h})\end{array}$ & $\begin{array}{c}R_{\max } \\
(\mathrm{mm} / \mathrm{h})\end{array}$ \\
\hline $13: 1220 / 05 / 03$ & 570 & 15 & 7.74 & 48.01 \\
\hline $16: 1227 / 06 / 03$ & 771 & 6 & 7.45 & 41.72 \\
\hline $13: 40$ 29/06/03 & 1346 & 15 & 1.07 & 4.66 \\
\hline $17: 3630 / 06 / 03$ & 750 & 18 & 4.08 & 30.23 \\
\hline $12: 03$ 02/07/03 & 885 & 20 & 8.89 & 82.31 \\
\hline 09:54 13/06/04 & 2979 & 46 & 5.13 & 55.63 \\
\hline $14: 22$ 02/07/04 & 432 & 1 & 2.20 & 3.50 \\
\hline $12: 24$ 05/07/04 & 564 & 36 & 3.34 & 37.93 \\
\hline $19: 2411 / 07 / 04$ & 552 & 16 & 3.20 & 26.42 \\
\hline $14: 18$ 18/07/04 & 678 & 13 & 5.11 & 29.46 \\
\hline $12: 03$ 21/07/04 & 1080 & 40 & 5.20 & 88.39 \\
\hline $15: 24$ 26/07/04 & 1578 & 46 & 3.81 & 90.42 \\
\hline $16: 4230 / 07 / 04$ & 921 & 41 & 6.51 & 68.58 \\
\hline 08:24 01/08/04 & 1239 & 46 & 6.66 & 64.52 \\
\hline $13: 12$ 08/08/04 & 1131 & 40 & 5.00 & 41.66 \\
\hline $15: 42$ 19/08/04 & 822 & 25 & 6.43 & 49.28 \\
\hline 09:54 02/09/04 & 834 & 37 & 3.47 & 35.22 \\
\hline $11: 18$ 04/09/04 & 756 & 28 & 2.30 & 25.91 \\
\hline $12: 1209 / 09 / 04$ & 612 & 32 & 8.14 & 43.77 \\
\hline $19: 5419 / 05 / 03$ & 234 & 6 & 9.08 & 49.02 \\
\hline $13: 4623 / 06 / 03$ & 398 & 8 & 14.93 & 57.41 \\
\hline 05:36 02/06/04 & 912 & 3 & 5.34 & 13.21 \\
\hline 02:12 04/06/04 & 480 & 1 & 3.44 & 3.57 \\
\hline $19: 1010 / 06 / 04$ & 278 & 2 & 3.02 & 6.96 \\
\hline $14: 4621 / 06 / 04$ & 482 & 14 & 2.17 & 14.99 \\
\hline $13: 40$ 03/07/04 & 566 & 4 & 9.63 & 34.54 \\
\hline $10: 03$ 21/08/04 & 675 & 23 & 10.97 & 35.06 \\
\hline $22: 48$ 20/05/03 & 60 & 2 & 0.74 & 0.99 \\
\hline 05:03 29/06/03 & 120 & 2 & 0.67 & 0.82 \\
\hline 03:22 16/06/04 & 132 & 2 & 1.83 & 3.22 \\
\hline 00:03 29/08/04 & 255 & 7 & 0.75 & 1.49 \\
\hline 00:03 10/09/04 & 249 & 4 & 1.26 & 2.57 \\
\hline $20: 3429 / 04 / 03$ & 540 & 31 & 6.20 & 26.46 \\
\hline $13: 4831 / 03 / 04$ & 408 & 2 & 6.62 & 13.98 \\
\hline $12: 03$ 21/04/03 & 855 & 9 & 4.82 & 13.46 \\
\hline $11: 5415 / 03 / 04$ & 558 & 11 & 7.68 & 15.51 \\
\hline $13: 3620 / 03 / 04$ & 426 & 3 & 4.43 & 10.93 \\
\hline $11: 03$ 21/03/04 & 759 & 27 & 5.04 & 53.85 \\
\hline $11: 5402 / 05 / 04$ & 252 & 2 & 1.29 & 3.32 \\
\hline $12: 2402 / 04 / 05$ & 1050 & 30 & 4.89 & 50.55 \\
\hline 11:04 08/04/05 & 608 & 2 & 2.31 & 2.80 \\
\hline $11: 5409 / 04 / 05$ & 588 & 3 & 3.23 & 8.19 \\
\hline $10: 3624 / 04 / 05$ & 492 & 2 & 6.03 & 12.20 \\
\hline $11: 3425 / 04 / 05$ & 350 & 3 & 5.40 & 16.51 \\
\hline
\end{tabular}

Accumulated rain gauge rainfall were averaged from rainfall $>0.5 \mathrm{~mm} / \mathrm{h} ; R_{\max }$ is the maximum rain gauge rainfall.

rainfall types. The first data set was $80 \%$ of available rainfall events in this study which consisted of 34 rainfall occasions during 2003-2005. All of these rainfall events were merged together and used for 
calibrating. Among these calibrated 34 rainfall events, 16,14 , and 4 events were classified as cumulonimbus, cumulus, and nimbostratus rainfall types, respectively. This data set was used for calibrating the climatological $Z-R$ relationship $\left(Z=a R^{b}\right.$ ) of the Pimai radar. The second data set was the remaining $20 \%$ of the available rainfall events which consisted of 5 cumulonimbus, 4 cumulus, and 1 nimbostratus rainfall events. This data set was used for validation purposes. It is to be noted that the classification of rainfall type used in this study followed the rainfall classification criteria based on 2-D CAPPI reflectivity data proposed by Chumchean et $\mathrm{al}^{44}$. Details of rainfall events used in this study are summarized in Table 1.

Parameters of climatological $Z-R$ relationship of the Pimai radar were calibrated using the first data set. Relationship between radar reflectivity $\left(\mathrm{mm}^{6} / \mathrm{m}^{3}\right)$ and rainfall intensity $(\mathrm{mm} / \mathrm{h})$ were investigated using a regression method. The $a$ and $b$ parameters of the $Z-R$ relationship were derived by minimizing mean square error between radar rainfall and corresponding rain gauge rainfall. Doelling et $\mathrm{al}^{45}$, Steiner and Smith ${ }^{46}$, and Hagen and Yuter ${ }^{11}$ used several years of disdrometer data to investigate the most suitable $b$ parameter of a $Z-R$ relationship. They found that the value of 1.5 was the most proper $b$ parameter. However, variations of the $b$ parameter does not affect the RMSE between radar and rain gauge rainfall much $^{47}$. Therefore, the $b$ parameter of 1.5 was used in this study. The calibration was performed in an hourly time-step. It was found that the climatological $Z-R$ relationship of the Pimai radar is $Z=56.5 R^{1.5}$. Comparison between initial radar rainfall estimates that were obtained by using the derived climatological $Z-R$ relationship and the corresponding hourly rain gauge data are presented in Fig. 3. This figure shows that radar rainfall calculated from the climatological $Z-R$ relationship was underestimated when compared with rain gauge data. It was evident that the bias which still remains in the initial radar rainfall estimates needs to be adjusted. This study focuses to remove the bias in radar rainfall estimates rather than removing all sources of systematic error.

A bias between radar rainfall and rain gauge rainfall can be removed using information provided by rain gauges. A bias adjustment factor $(G / R)$ can be derived from the ratio of accumulated rain gauge rainfall $(G)$ and accumulated radar rainfall $(R)$ that is estimated from an appropriate $Z-R$ relationship of the study area. Thereafter, final radar rainfall can be calculated by multiplying an initial radar rainfall with a suitable bias correction factor. Different bias adjustment techniques such as climatological mean

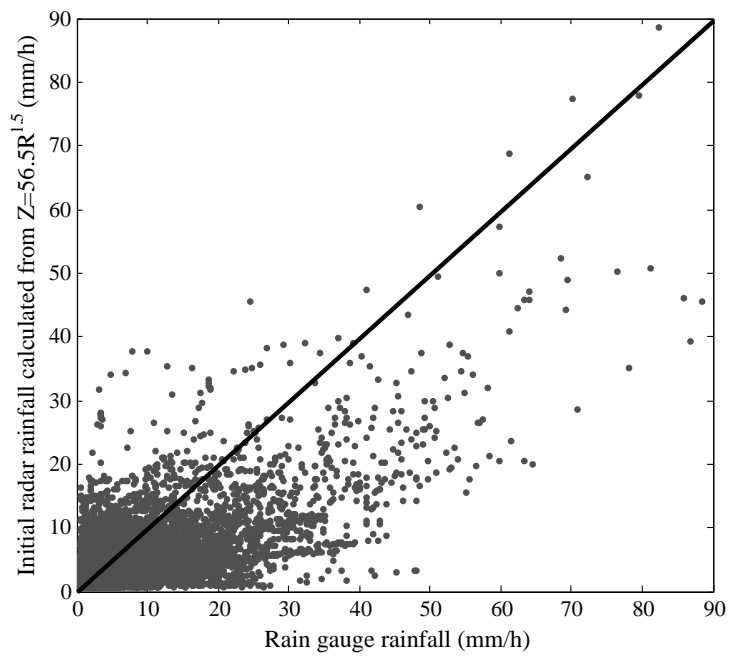

Fig. 3 Comparison between initial radar rainfall estimates using climatological $Z-R$ relationship $\left(Z=56.5 R^{1.5}\right)$ and corresponding hourly rain gauge rainfall data of the calibration events (34 events).

field bias correction (MFB), hourly mean field bias correction (HMFB), hourly range dependent mean field bias correction (HRMFB), and hourly local bias correction (HLB) have been used to remove bias in radar rainfall estimates when compared with rain gauge data. This study introduces the bias correction method based on the simple kriging technique. The accuracy of bias corrected radar rainfall based on these four bias correction methods was investigated. Details of these methods are explained below:

\section{Mean field bias correction (MFB)}

Mean field bias correction is the simplest method in which a bias correction factor is constant over time and space ${ }^{13-15}$. It is suitable for an area where a dense rain gauge network is available ${ }^{48}$. The mean field bias correction factor $(G / R)_{\mathrm{MFB}}$ can be calculated as follows:

$$
(G / R)_{\mathrm{MFB}}=\frac{\sum_{i=1}^{N} G_{i}}{\sum_{i=1}^{N} R_{i}},
$$

where $G_{i}$ is the accumulated rain gauge rainfall $(\mathrm{mm} / \mathrm{h})$ over the analysis period at gauge $i, R_{i}$ is the accumulated initial radar rainfall $(\mathrm{mm} / \mathrm{h})$ at gauge $i$, calculated using the climatological $Z-R$ relationship, and $N$ is the number of radar-gauge pairs data available. 


\section{Hourly mean field bias correction (HMFB)}

Rainfall characteristic varies in both space and time leading to a change in DSDs and consequently uncertainty in the $Z-R$ relationship. Hourly mean field bias correction (HMFB) method has been proposed to reduce bias due to temporal variation of DSDs. The studies of Smith and Krajewski ${ }^{49}$, Anagnostou et al ${ }^{50}$, Seo et $\mathrm{al}^{51}$, and Chumchean et al ${ }^{52}$ applied Kalman filtering techniques to predict and update a mean field bias in real-time. In their methods, the mean field bias was characterized as an autoregressive order one (AR1) model, with parameters being updated using a Kalman filter. Observation errors of mean field bias are required to use in these methods. However, high uncertainty still remains in the observation errors of mean field bias and the observation errors are generally not available for most of the radar sites. Hence, a simple hourly mean field bias correction factor at hour $t$ was used in this study which can be calculated as:

$$
(G / R)_{\mathrm{HMFB}_{t}}=\frac{\sum_{i=1}^{N} G_{i, t}}{\sum_{i=1}^{N} R_{i, t}}
$$

where $G_{i, t}$ is the rain gauge rainfall $(\mathrm{mm} / \mathrm{h})$ at gauge $i$ for hour $t, R_{i, t}$ is the initial radar rainfall $(\mathrm{mm} / \mathrm{h})$ at gauge $i$ for hour $t$, calculated using the climatological $Z-R$ relationship, and $N$ is the number of radar-gauge pairs data available at that hour.

\section{Hourly range dependent mean field bias correction (HRMFB)}

The effect of Earth's curvature and the increase of radar beam as a function of range from a radar site cause the observation altitude and radar measurement volume to increase with range from the radar, which leads to errors in radar rainfall estimates as a function of range. The error in initial radar rainfall estimate as a function of range from the Pimai radar site was investigated by considering the error between radar rainfall and rain gauge measurement at each rain gauge location using the equation proposed by Anagnostou et al $^{53}$. The error variance between initial hourly radar rainfall estimates and the corresponding rain gauge data of the 34 calibrated rainfall events is illustrated in Fig. 4.

From Fig. 4, it was evident that the error in initial radar rainfall estimates increases as a function of range from the radar site. The relationship between error variance of initial radar rainfall estimates and

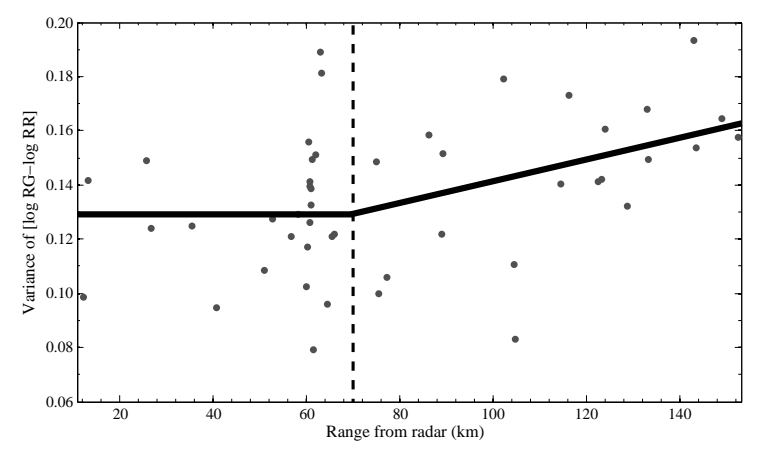

Fig. 4 Error variance of initial radar rainfall estimates of the calibrated rainfall events (34 events) at each rain gauge location.

distance from the radar site can be divided into two range intervals as illustrated in Fig. 4. The first range is the distance less than $70 \mathrm{~km}$ from the radar site and the second range is the distance beyond $70 \mathrm{~km}$. Relationships between error in radar rainfall estimates and distance from radar site for these two ranges can be written as:

$$
\sigma_{\mathrm{GR}}^{2}= \begin{cases}0.1320, & R_{0}<70 \\ 0.0003\left(R_{0}-70\right)+0.1320, & R_{0} \geqslant 70\end{cases}
$$

where $R_{0}$ is the distance from the radar site $(\mathrm{km})$, and $\sigma_{\mathrm{GR}}^{2}$ is the error variance in radar rainfall estimates at distance $R_{0}$ from the radar site.

It is to be noted that the result obtained from this study corresponded to the study of Chumchean et al ${ }^{54}$. They found that errors in initial radar rainfall estimates of the C-band Kurnell radar in Sydney, Australia, were constant for the range between 0 and $55 \mathrm{~km}$ from the radar and increased as a function of range beyond $55 \mathrm{~km}$ from the radar site. This corresponds to the fact that the effective range of S-band radar is further from the radar site than C-band radar. Since the error in initial radar rainfall estimates of the Pimai radar (as illustrated in Fig. 4) varied as a function of distance from the radar site at the range beyond $70 \mathrm{~km}$ from the radar, therefore bias adjustment factors for these two range intervals $(<70 \mathrm{~km}$ and $\geqslant 70 \mathrm{~km})$ should be different. Moreover, because DSDs change in both space and time, using range dependent hourly bias adjustment factors can reduce the error due to varying of DSDs in time. The hourly range dependent bias correction factor, $(G / R)_{\mathrm{HRMFB}_{t}}$, considered in this 
Table 2 Assessment of different semivariograms in root mean square standardized error, mean standardized error, root mean square error, and average standard error.

\begin{tabular}{|c|c|c|c|c|c|c|c|c|}
\hline \multirow{2}{*}{$\begin{array}{l}\text { Semivariogram } \\
\text { model }\end{array}$} & \multicolumn{2}{|c|}{ RMS standardized error } & \multicolumn{2}{|c|}{ Mean standardized error } & \multicolumn{2}{|c|}{ RMS error } & \multicolumn{2}{|c|}{ Average standard error } \\
\hline & Isotropic & Anisotropic & Isotropic & Anisotropic & Isotropic & Anisotropic & Isotropic & Anisotropic \\
\hline Circular & 0.974 & 0.974 & -0.013 & -0.013 & 111.9 & 113.7 & 111.4 & 116.1 \\
\hline Spherical & 0.950 & 0.950 & -0.016 & -0.016 & 110.8 & 112.5 & 116.1 & 117.5 \\
\hline Tetraspherical & 0.932 & 0.936 & -0.018 & -0.018 & 110.0 & 111.6 & 117.5 & 118.7 \\
\hline Pentaspherical & 0.918 & 0.923 & -0.019 & -0.020 & 109.5 & 111.0 & 118.8 & 119.8 \\
\hline Exponential & 0.882 & 0.893 & -0.020 & -0.020 & 109.9 & 111.4 & 124.0 & 124.0 \\
\hline Gaussian & 1.084 & 1.066 & -0.008 & -0.008 & 115.2 & 116.9 & 105.8 & 109.2 \\
\hline Rational quadratic & 0.917 & 0.913 & -0.016 & -0.018 & 107.7 & 108.8 & 117.2 & 118.7 \\
\hline Hole effect & 1.019 & 0.997 & -0.028 & -0.026 & 110.0 & 111.2 & 107.6 & 111.9 \\
\hline Bessel- $K$ & 1.051 & 0.915 & -0.013 & -0.019 & 112.8 & 110.7 & 106.9 & 120.4 \\
\hline Bessel- $J$ & 1.000 & 1.020 & -0.003 & -0.021 & 109.1 & 111.7 & 108.5 & 110.9 \\
\hline Stable & 0.933 & 0.905 & -0.018 & -0.020 & 109.4 & 111.1 & 116.4 & 122.2 \\
\hline
\end{tabular}

study is:

$$
(G / R)_{\mathrm{HRMFB}_{j, t}}=\frac{\sum_{i=1}^{N} G_{i, j, t}}{\sum_{i=1}^{N} R_{i, j, t}},
$$

where $G_{j, i, t}$ is the rain gauge rainfall $(\mathrm{mm} / \mathrm{h})$ at gauge $i$ located within range $j$ for hour $t, R_{j, i, t}$ is the initial radar rainfall $(\mathrm{mm} / \mathrm{h})$ at gauge $i$ located within range $j$ for hour $t$, calculated using the climatological $Z-R$ relationship, and $N$ is the number of radar-gauge pairs data available at range $j$ for that hour.

\section{Hourly local bias correction (HLB)}

Different rainfall characteristic causes a difference in DSDs of each type of rainfall, and consequently leads to variation of parameters of $Z-R$ relationship. Hourly local bias correction method (HLB) is proposed to remove source of bias in radar rainfall estimates due to uncertain $Z-R$ relationship. Local bias adjustment factor is applied to a region that has the same climatological rainfall characteristic. In this study, 50-year averages of annual rainfall data of 188 uniformly distributed daily rain gauges located under the radar umbrella (as illustrated in Fig. 1) and its vicinity area were used to describe climatological spatial pattern of rainfall in the study area based on simple kriging techniques. It is vital to select an appropriate model to estimate spatial statistics as each model gives different values for nugget variance and range which are essential for geostatistical analyses ${ }^{55}$. Hence, in this study 11 different semivariogram models including circular, spherical, tetraspherical, pentaspherical, exponential, gaussian, rational quadratic, hole effect,
Bessel- $K$, Bessel- $J$, and stable based on isotropic and anisotropic relations were tested for their appropriate rainfall parameter data set. Calibration process was performed in order to predict the parameters while cross-validation process was carried out to determine of which model provided the best predictions. For a model that provides most accurate predictions, the mean standardized error should be close to 0 , the root mean square error and average standard error should be as small as possible, and the root mean square standardized error should be close to 1 . When the average estimated prediction standard errors from cross-validation are close to the root mean square error, then one can be confident that the prediction standard errors are appropriate ${ }^{56-58}$. Assessment of these 11 semivariograms were presented in Table 2. The results given in Table 2 show that using simple kriging technique with isotropic Bessel- $J$ semivariogram model which is a function of the distance gave the root mean square standardized error to be closest to 1, mean standardized error to be closest to 0 , and root mean square error to be closest to average standard error between the observed and predicted rainfall at the cross-validated rain gauge stations. Therefore, this model was considered to be the best model for providing most accurate spatial average annual rainfall data in the study area. The Bessel- $J$ model had better performance over the other models can also be explained in terms of mathematical point of view that it provided more flexibility in degree of smoothness when modelling a physical process than other models ${ }^{41}$.

Isotropic semivariogram model was then applied to the average annual rainfall data of 188 rain gauge stations to compute the climatological spatial pattern of rainfall in the study area, which is shown in Fig. 5. 


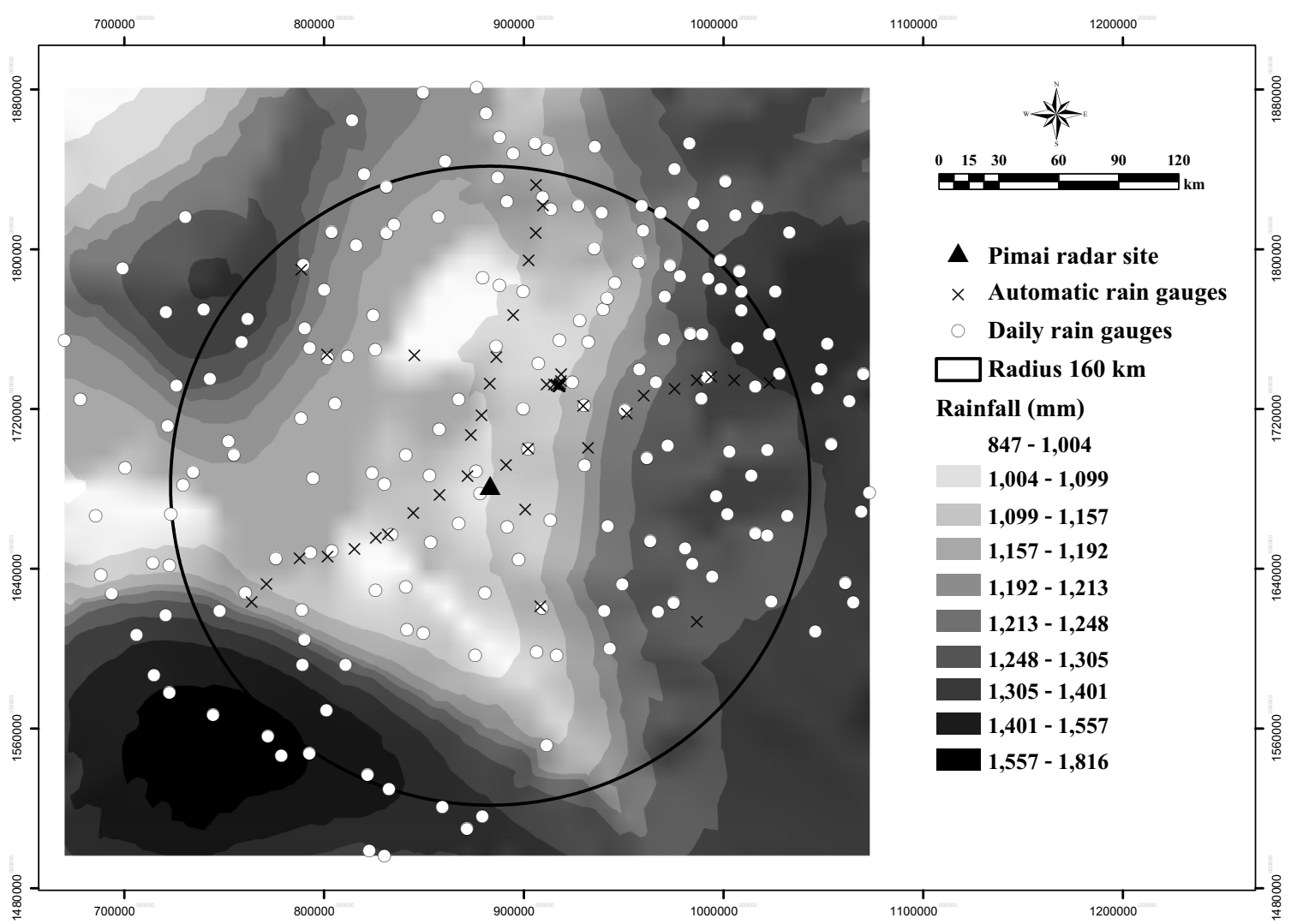

Fig. 5 Climatological spatial rainfall pattern of the study area calculated from 50-year average annual rainfall data of 188 daily rain gauge stations by using simple kriging with isotropic Bessel- $J$ semivariogram model.

Temporal correlation between annual average of 50year rainfall data is negligible in this study because local hourly bias adjustment factor has been used for temporal bias correction of each region that has the same climatological rainfall characteristic. Since spatial correlation between annual average rain gauge rainfall data was used to identify regions that have the same rainfall characteristic based on simple kriging method. Hence, the HLB method can only be applied to areas where rain gauge networks are dense with long historical rainfall records.

DSDs that are measured by radar have fundamental influence on parameters of $Z-R$ relationship. This study assumes that climatological spatial pattern of rainfall can be used to represent average DSDs of each local area. Consequently, within any local area, it is considered to have the same hourly bias correction factor. Since rainfall intensity varies to DSDs, the proposed HLB method is considered to be accounted for average rainfall intensity of each local area. The climatological spatial rainfall pattern shown in Fig. 5 was used to represent local bias correction areas of the HLB method. For each local area, an hourly bias correction factor was calculated by using $G / R$ pairs of rain gauges located inside the area. These hourly local bias correction factors were used to adjust initial radar rainfall estimates of their corresponding areas. The hourly local bias correction factor, $(G / R)_{\mathrm{HLB}_{t}}$ can be written as:

$$
(G / R)_{\mathrm{HLB}_{t}}=\frac{\sum_{i=1}^{N} G_{k, i, t}}{\sum_{i=1}^{N} R_{k, i, t}},
$$

where $G_{k, i, t}$ is rain gauge rainfall $(\mathrm{mm} / \mathrm{h})$ at gauge $i$ located within local area $k$ for hour $t, R_{k, i, t}$ is initial radar rainfall $(\mathrm{mm} / \mathrm{h})$ at gauge $i$ located within local area $k$ for hour $t$, calculated using climatological $Z-R$ relationship, $k$ is a local area that has the same climatological rainfall characteristic, and $N$ is number of radar-gauge pairs data available at area $k$ for that hour. 


\section{TEST EFFICIENCY OF BIAS CORRECTION METHODS}

Performances of four bias correction methods described in the previous sections and no-bias correction method (NBC) were investigated by using 10 rainfall events of the second data set (validated data set). To perform the analysis, 10 rainfall events of the validation data set were merged. Then, the initial radar rainfall for the ensemble of 10 rainfall events of the validation data set using climatological $Z-R$ relationship ( $Z=56.5 R^{1.5}$ ) of the Pimai radar was calculated. For each hour, the validation data set was randomly divided into two groups. The first group was based on $80 \%$ of available automatic rain gauges of that hour (39 gauges), thereafter referred as calibratedgauges. The second group was the remaining gauges (10 gauges) of that hour, so called cross-validated gauges. Rain gauge rainfall and corresponding initial radar rainfall obtained above of the calibrated and cross-validated gauges were derived. Hourly $G / R$ ratios were calculated based on the randomly selected calibrated-gauges by following the four bias correction methods. For HRMFB and HLB methods, if in any hour, the number of calibrated-gauges within a considered range interval (for HRMFB) and local adjustment area (for HLB) was less than $10 \%$ of the total number of calibrated-gauges of that hour, the $G / R$ of that range interval and local adjustment area were assigned to be equal to 1 . The final radar rainfall was obtained by multiplying the hourly $G / R$ ratios calculated from the four different bias correction methods by initial radar rainfall rate of the calibrated-gauges and cross-validated gauges. Finally, we computed the RMSEs between rain gauge rainfall and radar rainfall estimates that were obtained from different bias correction methods for the calibrated and cross-validated gauges. These RMSEs were used to evaluate the accuracy of radar rainfall derived from the four bias correction methods which can be written as:

$$
\mathrm{RMSE}=\sqrt{\frac{1}{N} \sum_{t=1}^{N_{t}} \sum_{i=1}^{N_{G}}\left(R_{i, t}-G_{i, t}\right)^{2}}
$$

where $R_{i, t}$ is the radar-rainfall accumulations at the rain gauge $i$ for hour $t, G_{i, t}$ is the corresponding rainfall for hour $t, N_{G}$ is the number of rain gauges that measure non-zero rainfall $N_{t}$ is the number of time periods (hours), and $N$ is the number radar-gauge pairs used in the computation (i.e., calibrated-gauges or cross-validated gauges)

The steps described above were repeated 500 times for different random selections of the
Table 3 Mean of RMSE results of 500 randomly selected calibrated and cross-validated gauges of different bias correction methods.

\begin{tabular}{lcc}
\hline Bias correction method & \multicolumn{2}{c}{ RMSE (mm/h) } \\
\cline { 2 - 3 } & Calibration & $\begin{array}{c}\text { Cross- } \\
\text { validation }\end{array}$ \\
\hline No bias correction (NBC) & 6.27 & 5.77 \\
Mean field bias correction (MFB) & 6.09 & 5.67 \\
$\begin{array}{l}\text { Hourly mean field bias correction } \\
\text { (HMFB) }\end{array}$ & 5.37 & 5.62 \\
$\begin{array}{l}\text { Hourly range dependent mean } \\
\text { field bias correction (HRMFB) }\end{array}$ & 5.24 & 5.31 \\
$\begin{array}{l}\text { Hourly local bias correction } \\
\text { (HLB) }\end{array}$ & 5.22 & 5.09 \\
\hline
\end{tabular}

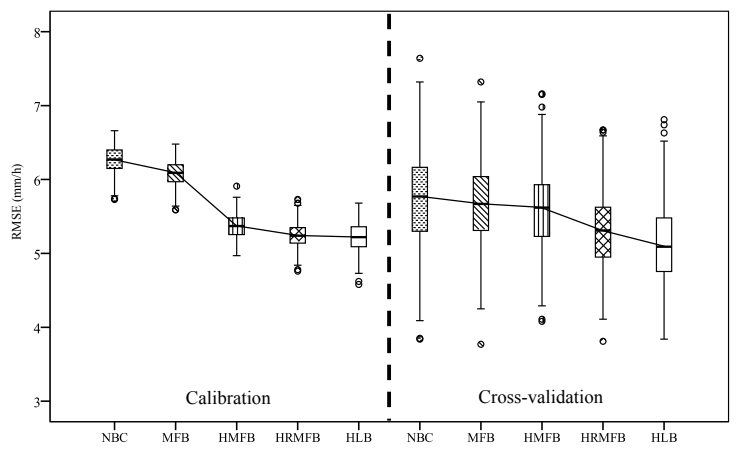

Fig. 6 Variation of RMSE across the 500 randomly selected calibrated and cross-validated gauges for different bias correction methods.

calibrated and cross-validated gauge networks. Statistical measures of RMSE results of 500 randomly selected calibrated and cross-validated gauge networks are presented in Table 3. The boxplots presented in Fig. 6 reflect the variations in the RMSE across the 500 sub-samples that were used in the analysis. The results showed that the HLB approach resulted in the lowest RMSE compared to other methods for both calibrated and cross-validated gauges. The results presented in Fig. 6 also show the stepwise decrease in RMSE values with added levels of complexity in bias correction methods.

To test statistical difference between RMSE results of different bias correction methods, one-tailed $t$-test was performed with the results presented in Table 4 and Table 5. The results of one-tailed $t$-test of 500 randomly selected calibrated-gauge and cross-validated gauge networks illustrated in Table 4 showed that the RMSEs of the calibration case revealed significant differences between HLB and the 
Table 4 Comparisons for RMSE results of the different bias correction methods for the calibration case.

\begin{tabular}{lllccc}
\hline Pair No. & Method & Mean & Std. error & $p$-value & $t$-value \\
\hline 1 & HLB & 4.085 & 0.0051 & 0.000 & -323.587 \\
& NBC & 5.054 & 0.0059 & & \\
2 & HLB & 4.085 & 0.0051 & 0.000 & -346.105 \\
& MFB & 4.980 & 0.0051 & & \\
3 & HLB & 4.085 & 0.0051 & 0.000 & -133.460 \\
& HMFB & 4.349 & 0.0051 & & \\
4 & HLB & 4.085 & 0.0051 & 0.000 & -35.378 \\
& HRMFB & 4.164 & 0.0054 & & \\
\hline
\end{tabular}

Table 5 Comparisons for RMSE results of different bias correction methods for the cross-validation case.

\begin{tabular}{llcccc}
\hline Pair No. & Method & Mean & Std. error & $p$-value & $t$-value \\
\hline 1 & HLB & 4.577 & 0.0211 & 0.000 & -48.569 \\
& NBC & 5.037 & 0.0195 & & \\
2 & HLB & 4.577 & 0.0211 & 0.000 & -26.594 \\
& MFB & 4.867 & 0.0159 & & \\
3 & HLB & 4.577 & 0.0211 & 0.000 & -42.175 \\
& HMFB & 4.811 & 0.0197 & & \\
4 & HLB & 4.577 & 0.0211 & 0.000 & -12.285 \\
& HRMFB & 4.663 & 0.0235 & & \\
\hline
\end{tabular}

other four methods $(p<0.05)$ at $95 \%$ confidence level. For the calibration case, the estimated $G / R$ ratios were applied to the same data set as they had been derived from. Therefore, a more complicated method for calculating $G / R$ ratios, gave a higher accuracy result. However, this was not always true for cross-validation case since the calculated $G / R$ ratios derived from the calibrated-gauges were applied to the cross-validated gauges which had not been used for estimating those $G / R$ ratios. The onetailed $t$-test of RMSE results of cross-validated gauges presented in Table 5 showed that the RMSEs of the cross-validation case revealed significant differences between HLB and the other four methods $(p<0.05)$ at $95 \%$ confidence level. This corresponds to the fact that $G / R$ ratios varied by DSDs using HLB method can help to reduce temporal and spatial uncertainty in parameters of the $Z-R$ relationship. The RMSE results of the calibration and cross-validation cases confirm the effectiveness of the HLB method.

\section{CONCLUSIONS}

The bias correction method based on geostatistical technique was proposed to reduce uncertainty in the $Z-R$ relationship. Simple kriging with 11 different semivariogram models including circular, spherical, tetraspherical, pentaspherical, exponential, gaussian, rational quadratic, hole effect, Bessel- $K$, Bessel- $J$, and stable with both isotropic and anisotropic relations were used to estimate climatology spatial patterns of average annual rainfall in the study area based on 50year averages of annual rainfall data recorded from the network of 188 daily rain gauges. The most accurate climatological spatial pattern of average annual rainfall in the study area was used to identify local bias correction areas of the proposed HLB method. Effectiveness of various bias correction methods which are appropriate for operational use were tested using 10 validation rainfall events during 2004-2005. Several statistical measures were computed to evaluate performance of these bias correction methods.

It is to be noted that the results presented in this study cannot be generalized and transferred to other locations but the proposed HLB method can easily be applied to other locations where rain gauge networks are dense with long historical records. These rainfall data are required for analysing climatological rainfall characteristic of a study area.

Acknowledgements: The authors gratefully acknowledge the Bureau of Royal Rainmaking and Agricultural Aviation (Thailand) and the Royal Irrigation Department for providing the radar and rain gauge data.

\section{REFERENCES}

1. Linsley RK, Kohler MA, Paulhus JL (1949) Applied Hydrology. McGraw-Hill, New York.

2. Singh VP, Chowdhury K (1986) Comparing some methods of estimating mean areal rainfall. Water Resour Bull 222, 275-82.

3. Ashraf M, Loftis JC, Hubbard KG (1997) Application of geostatisticals to evaluate partial weather station network. Agr Forest Meteorol 84, 255-71.

4. Goovaerts P (2000) Geostatistical approaches for incorporating elevation into the spatial interpolation of rainfall. J Hydrol 228, 113-29.

5. Teegavarapu RSV (2007) Use of universal function approximation in variance-dependent surface interpolation method: An application in hydrology. J Hydrol 322, 16-29.

6. Chumchean S, Seed A, Sharma A (2006) Correcting of radar mean field bias using Kalman filtering approach. J Hydrol 317, 123-37.

7. Joss J, Lee R (1995) The application of radar-gauge comparisons to operational precipitation profile corrections. J Appl Meteorol 34, 2612-30.

8. Anagnatsou EN, Morales CA (2001) Rainfall estimation from TOGA radar observations during the LBA field campaign. J Geophys Res 107, 66-91.

9. Chumchean S, Sharma A, Seed A (2004) Application of scaling in radar reflectivity for correcting range de- 
pendent bias in climatological radar rainfall estimates. J Atmos Ocean Tech 21, 1545-56.

10. Marshall JS, Palmer WM (1948) The distribution of raindrops with size. J Atmos Ocean Sci 5, 165-6.

11. Hagen M, Yuter SE (2003) Relations between radar reflectivity, liquid water content, and rainfall rate during the MAPSOP. Q J Roy Meteorol Soc 129, 477-93.

12. Chumchean S, Seed A, Sharma A (2008) An operational approach for classifying storms in real-time radar rainfall estimation. $J$ Hydrol 363, 1-17.

13. Wilson JW (1970) Integration of radar and raingauge data for improved rainfall measurements. J Appl Meteorol 9, 489-97.

14. Steiner M, Smith JA, Burges SJ, Alonso CV, Darden RW (1999) Effect of bias adjustment and rain gauge data quality control on radar rainfall estimation. Water Resour Res 35, 2487-503.

15. Zhang ZY, Koren V, Smith M, Reed S, Wang D (2004) Use of next generation weather radar data and basin disaggregation to improve continuous hydrograph simulations. J Hydrolog Eng 9, 103-15.

16. Krajewski WF, Vignal B, Seo B-C, Villarini G (2011) Statistical model of the range-dependent error in radarrainfall estimates due to vertical profile of reflectivity. J Hydrol 402, 306-16.

17. Borga M, Tonelli F (2000) Adjustment of rangedependent bias in radar rainfall estimates. Phys Chem Earth 25, 909-14.

18. Borga M, Tonelli F, Moore RJ, Andrieu H (2002) Longterm assessment of bias adjustment in radar rainfall estimation. Water Resour Res 38, 1226.

19. Brandes EA (1975) Optimizing rainfall estimates with the aid of radar. J Appl Meteorol 14, 1339-45.

20. Michelson DB, Koistinen J (2000) Gauge-radar network adjustment for the Baltic Sea Experiment. Phys Chem Earth 25, 915-20.

21. Wood SJ, Jones DA, Moore RJ (2000) Static and dynamic calibration of radar data forhydrological use. Hydrol Earth Syst Sci 4, 545-54.

22. Habib E, Larson BF, Nuttle WK, Rivera-Monroy VH, Nelson BR, Meselha EA, Twilley RR (2008) Effect of rainfall spatial variability and sampling on salinity prediction in an estuarine system. J Hydrol 350, 56-67.

23. AghaKouchak A, Habib E, Bardossy A (2010) Modeling radar rainfall estimation uncertainties: random error model. J Hydraul Eng 15, 265-74.

24. Mandapaka PV, Villarini G, Seo B-C, Krajewski WF (2010) Effect of radar-rainfall uncertainties on the spatial characterization of rainfall events. J Geophys Res 115, D17110.

25. Habib E, Aduvala AV, Meselhe EA (2008) Analysis of radar-rainfall error characteristics and implications for streamflow simulation uncertainty. Hydrolog Sci J $\mathbf{5 3}$ 568-87.

26. AghaKouchak A, Bardossy A, Habib E (2010) Conditional simulation of remotely sensed rainfall data using a non-Gaussian v-transformed copula. Adv Water
Resour 33, 624-34.

27. Velasco C, Sempere D, Cassiraga E, Gomez J (2009) A non-parametric automatic blending methodology to estimate rainfall fields from rain gauge and radar data. Adv Water Resour 32, 986-1002.

28. Haberlandt U (2007) Geostatistical interpolation of hourly precipitation from rain gauges and radar for a large-scale extreme rainfall event. J Hydrol 332, 144-57.

29. Goudenhoofdt E, Delobbe L (2009) Evaluation of radar-gauge merging methods for quantitative precipitation estimates. Hydrol Earth Syst Sci 13, 195-203.

30. Li B, Eriksson M, Srinivasan R, Sherman M (2008) A geostatistical method for Texas NexRad data calibration. Environmetrics 19, 1-19.

31. Yuter S, House RA (1997) Measurements of raindrop size distributions over the Pacific warm pool and implications for Z-R relations. J Appl Meteorol 36, 847-67.

32. Uijlenhoet R, Steiner M, Smith JA (2003) Variability of raindrop size distributions in a squall line and implications for radar rainfall estimation. J Hydrometeorol 4, 43-61.

33. Lee GW, Zawadzki I (2005) Variability of drop size distributions: Noise and noise filtering in disdrometric data. J Appl Meteorol 44, 634-52.

34. Givone C, Meignien X (1990) Influence of topography on spatial distribution of rain. In: Molnâr L (ed) Hydrology of Mountainous Areas, IAHS Publication No. 190, pp 57-65.

35. Hevesi JA, Flint AL, Istok JD (1992) Precipitation estimation in mountainous terrain using multivariate geostatistics. Part I: Structural analysis. J Appl Meteorol 31, 661-76.

36. Hevesi JA, Flint AL, Istok JD (1992) Precipitation estimation in mountainous terrain using multivariate geostatistics. Part II: Isohyetal maps. J Appl Meteorol 31, 677-88.

37. Kyriakidis PC, Miller NL, Kim J (2004) A spatial time series framework for simulating daily precipitation at regional scales. J Hydrol 297, 236-55.

38. Teegavarapu RSV, Chandramouli V (2005) Improved weighting methods, deterministic and stochastic datadriven models for estimation of missing precipitation records. J Hydrol 312, 191-206.

39. Sen Roy S, Balling RC (2005) Harmonic and simple kriging analyses of diurnal precipitation pattern in Puerto Rico. Caribb J Sci 41, 181-8.

40. Goovaerts P (1997) Geostatistics for Natural Resources Evaluation, Oxford, New York, N.Y., 483 p.

41. ESRI (2008) ArcGIS Desktop 9.3 user manual, Redlands, CA, USA.

42. Futon RA, Breidenbach JP, Seo DJ, Miller DA, O'Brannon T (1998) The WSD-88D rainfall algorithm. Weather Forecast 13, 377-95.

43. Dinku T, Anagnostou EN, Borga M (2002) Improving radar-based estimation of rainfall over complex terrain. J Appl Meteorol 41, 1163-78. 
44. Chumchean S, Aungsuratana P, Khommuang A, Hanchoowong R (2009) Study of rain-cloud characteristics using weather radar data. Proc., 18th MODSIM 2009 Congress, Cairns, Australia.

45. Doelling IG, Joss J, Riedl J (1998) Systematic variations of Z-R relationships from drop size distributions measured in northern Germany during seven years. Atmos Res 47-48, 635-49.

46. Steiner M, Smith JA (2000) Reflectivity, rain rate, and kinetic energy flux relationships based on raindrop spectra. Bull Am Meteorol Soc 39, 1923-40.

47. Seed A, Jordan P (2002) MapView 2-Viewers for radar and rainfall data. Developed by Hydrology Unit and Bureau of Meteorology Research Centre, Australian Bureau of Meteorology.

48. Gjertsen U, Salek M, Michelson DB (2004) Gauge adjustment of radar-based precipitation estimates in Europe. Proceedings of ERAD 2004, 7-11.

49. Smith JA, Krajewski WF (1991) Estimation of mean field bias of radar rainfall estimates. $J$ Appl Meteorol 30, 397-412.

50. Anagnostou EN, Krajewski WF, Seo DJ, Johnson ER (1998) Mean-field rainfall bias studies for WSR-88D. J Hydrolog Eng 3, 149-59.

51. Seo DJ, Breidenbach JP, Johnson ER (1999) Real-time estimation of mean field bias in radar rainfall data. J Hydrol 223, 131-47.

52. Chumchean S, Sharma A, Seed A (2006) An integrated approach to error correction for real-time radar-rainfall estimation. J Atmos Ocean Tech 23, 67-79.

53. Anagnostou EN, Krajewski WF, Smith JA (1999) Uncertainty quantification of mean-areal radar-rainfall estimates. J Atmos Ocean Tech 16, 206-15.

54. Chumchean S, Sharma A, Seed A (2003) Radar rainfall error variance and its impact on radar rainfall calibration. Phys Chem Earth 28, 27-39.

55. Trangmar BB, Yost RS, Uehara G (1985) Application of geostatistics to spatial studies of bsoil properties. Adv Agron 38, 45-94.

56. Gundogdu KS, Guney I (2007) Spatial analyses of groundwater levels using universal kriging. J Earth Syst Sci 116, 49-55.

57. Asa E, Saafi M, Membah J, Billa A (2012) Comparison of linear and nonlinear kriging methods for characterization and interpolation of soil data. J Comput Civ Eng 26, 11-8.

58. Jayeoba OJ, Sangari DU, Alabi RT (2012) Geostatistical analyses of the spatial variation of soil reaction $(\mathrm{pH})$ in Nasarawa State, North Central Nigeria. Int J Sci Adv Tech 2, 17-25. 